University of Louisville

ThinkIR: The University of Louisville's Institutional Repository

Electronic Theses and Dissertations

$12-2019$

\title{
Disentangling the negativity bias: 7-9-month-old crawling and non- crawling infants' responses to fearful and angry expressions.
}

Katherine C. Dixon

University of Louisville

Follow this and additional works at: https://ir.library.louisville.edu/etd

Part of the Developmental Psychology Commons

\section{Recommended Citation}

Dixon, Katherine C., "Disentangling the negativity bias: 7-9-month-old crawling and non-crawling infants' responses to fearful and angry expressions." (2019). Electronic Theses and Dissertations. Paper 3314. https://doi.org/10.18297/etd/3314

This Doctoral Dissertation is brought to you for free and open access by ThinkIR: The University of Louisville's Institutional Repository. It has been accepted for inclusion in Electronic Theses and Dissertations by an authorized administrator of ThinkIR: The University of Louisville's Institutional Repository. This title appears here courtesy of the author, who has retained all other copyrights. For more information, please contact thinkir@louisville.edu. 
DISENTANGLING THE NEGATIVITY BIAS: 7 - 9-MONTH-OLD CRAWLING AND NON-CRAWLING INFANTS' RESPONSES TO FEARFUL AND ANGRY EXPRESSIONS

\author{
By \\ Katherine C. Dixon \\ B.A., University of Tennessee at Knoxville, 2007 \\ M.A., University of Tennessee at Knoxville, 2014 \\ M.S., University of Louisville, 2017

\begin{abstract}
A Dissertation
Submitted to the Faculty of the

College of Arts and Sciences of the University of Louisville

in Partial Fulfillment of the Requirements

for the Degree of
\end{abstract}

Doctor of Philosophy in Experimental Psychology

Department of Psychological and Brain Sciences

University of Louisville

Louisville, Kentucky

December 2019 

DISENTANGLING THE NEGATIVITY BIAS: 7 - 9-MONTH-OLD CRAWLING AND NON-CRAWLING INFANTS' RESPONSES TO FEARFUL AND ANGRY EXPRESSIONS

By

Katherine C. Dixon

B.A., University of Tennessee at Knoxville, 2007

M.A., University of Tennessee at Knoxville, 2014

M.S., University of Louisville, 2017

A Dissertation Approved on:

November $20^{\text {th }}, 2019$

by the following Dissertation Committee:

Dr. Cara Cashon (Dissertation Director)

Dr. Judith Danovitch

Dr. Guy Dove

Dr. Carolyn Mervis

Dr. Paul Rosen 


\section{ACKNOWLEDGEMENTS}

First I would like to express my deep gratitude to my advisor, Dr. Cara Cashon. Without her support and guidance I would not have been able to complete this project. Thanks for teaching me what it means to be a good scientist.

I would also like to thank the members of my Dissertation Committee for their guidance and feedback both during the dissertation proposal and defense processes.

Thanks to my lab mates, past and present. Thanks to Dr. Nick Holt for never letting me take things too seriously. Thanks to Nonah Olesen for her cheerleading and emotional support. And thanks to Katie Kaufling for her constant positive attitude.

Thanks to all of the undergraduate research assistants that have worked in the Infant Cognition Lab over the past 5.5 years, specifically Maddie, Malaya, and TiShauna. Without them my videos would never have gotten coded.

Also, I greatly appreciate the local families who volunteered with their babies to participate in this study.

I would also like to thank my teammates, the Derby City Roller Girls. Being able to participate in a contact sport does wonders for work and school frustrations.

And finally, I would like to thank my family for their support- specifically Mom, Dad, and Edgar. 


\title{
ABSTRACT \\ DISENTANGLING THE NEGATIVITY BIAS: 7 - 9-MONTH-OLD CRAWLING AND NON-CRAWLING INFANTS' RESPONSES TO FEARFUL AND ANGRY EXPRESSIONS
}

\author{
Katherine C. Dixon \\ December $13^{\text {th }}, 2019$
}

Understanding the origins of the negativity bias in infancy and how it develops is important for building a complete understanding of emotion perception. The goal of the present study was to 1) examine attentional biases for emotional expressions in infants between 7-9 months of age, specifically the bias for fearful and angry expressions, 2) examine how the onset of crawling is related to these biases and what that suggests about the mechanism underlying emotion preference in infants, and 3) examine how infant expression production differs when viewing different facial expressions. Infant attention biases to fearful, angry, happy, and neutral facial expressions were measured using a paired comparison paradigm. Infant crawling status was assessed by an in-lab crawling test as well as a parent report measure. Infant expression production was measured during singly presented face stimuli using a novel program that codes micro-expressions from video (Affectiva). Results of the study 1) demonstrated that there was an overall preference for the fearful expression regardless of expression pairing, and that this preference was specific only to fear, 2) demonstrated that the robust fear bias seen in 6-9month-olds is unrelated to the changes in the emotional environment caused by crawling, and 3) provided tentative evidence to suggest that infants react differently to fearful and 
angry faces in terms of both visual attention and affective response. Implications and limitations of these findings are discussed, along with ideas for future directions. 


\section{TABLE OF CONTENTS}

PAGE

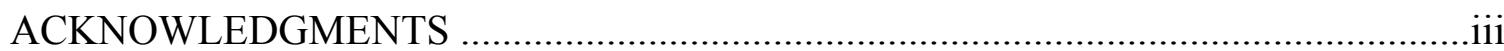

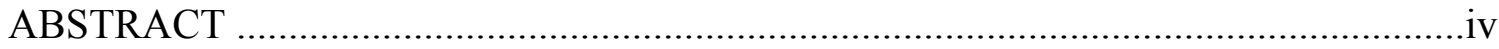

LIST OF TABLES ...........................................................................................

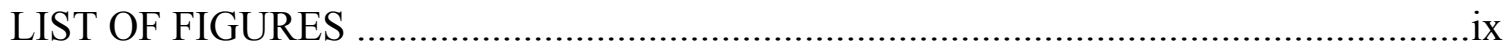

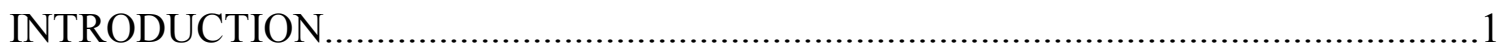

Does the Negativity Bias Originate in Infancy? ...................................................

Is Crawling Experience Related to Infants' Attention to Angry Expressions?.......7

Do Infants' Affective Responses Differ For Fearful and Angry Faces?.................9

The Present Study ............................................................................................11

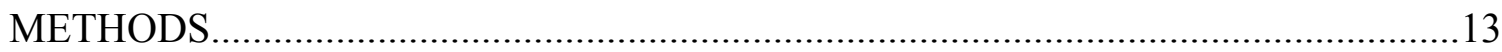

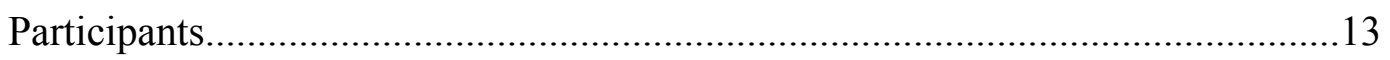

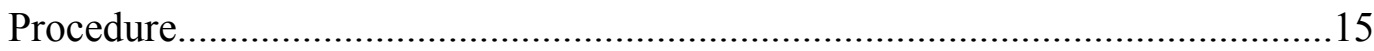

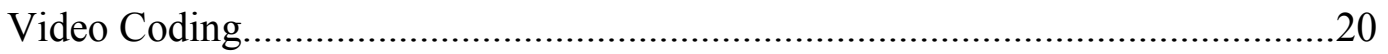

RESULTS

Emotion Bias and Crawling Experience...........................................................22

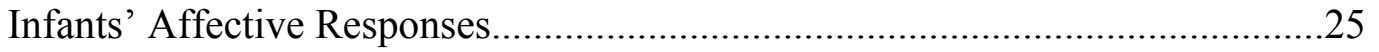


DISCUSSION.

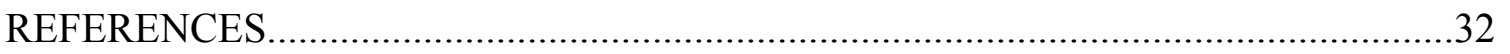

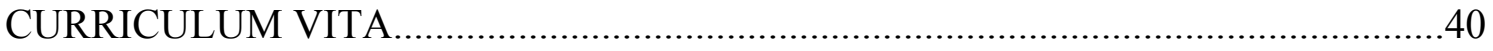




\section{LIST OF TABLES}

TABLE

1. AUs and Corresponding Affective Measures of Interest

2. Demographic Characteristics of Infants by Crawling Group

3. Mean Look Times (in seconds) to Each Expression in Expression Pairs .24

4. Statistics for Non-Significant Interactions in the 6, 2(Expression) X 2(Crawling Status) ANOVAs

5. Mean Negative AU Intensity to Each Expression. 


\section{LIST OF FIGURES}

$\begin{array}{ll}\text { FIGURE PAGE } & \text { PUT }\end{array}$

1. Motor Development Questionnaire..................................................................

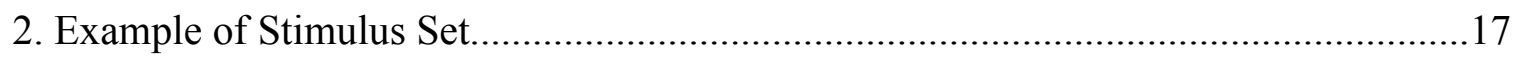

3. Stimulus Presentation for Emotion Bias and Affective Response Phases....................18

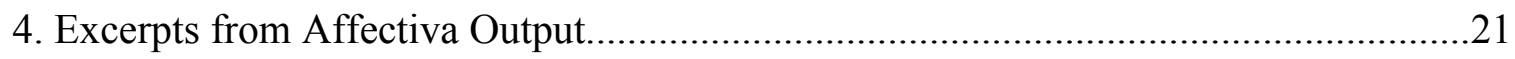

5. Mean Look Time in Seconds for Each Emotion Pair................................................23 


\section{INTRODUCTION}

Attending to the facial expressions of others is vital for interacting effectively in our social world. The ability to quickly attend to and maintain focus on certain facial expressions allows an individual to process socio-emotional information conveyed in expressions quickly. For example, being able to quickly detect and focus on a fearful face of another may allow a person to respond to a dangerous situation more rapidly. For adults and children, some facial expressions have more impact on attention than do others. Attentional biases for emotional facial expressions have been studied extensively in adults and children (e.g., Pool, Brosch, Delplanque, \& Sander, 2015), with both adults (for review, see Vaish, Grossmann, \& Woodward, 2008) and children showing a bias for negative socio-emotional information, which includes negative facial expressions (e.g., Ma, Twomey, \& Westerman, 2019). This phenomenon is known as the "negativity bias."

Understanding the origins of the negativity bias and how it develops is important for building a complete understanding of emotion perception. It has been hypothesized that changes in the emotional environment of the infant, i.e., changes in the types of expressions the infant experiences, alter infants' attentional biases (e.g., Heck, Hock, White, Jubran, \& Bhatt, 2016; Peltola, Leppänen, \& Hietanen, 2011). The primary goal of the present study was to investigate attentional biases for facial expressions (i.e., happy, neutral, angry, and fear) in infants between 7-9 months of age. Of particular interest was whether or not infants at this age would have a general bias toward negative facial expressions (angry and fear) as has been found in children and adults (e.g. 
Leppänen, Cataldo, Enlow, \& Nelson, 2018; Lobue, 2009; Vaish et al., 2008;

Vuilleumier, 2002). The onset of crawling, which typically occurs between 6-8 months of age (e.g. Adolph, Vereijken, \& Denny, 1998), has been shown to be related to an increase in angry emotions in the infant environment (e.g., Campos, Kermoian, \& Zumbahlen, 1992; Pemberton Roben et al., 2012; Zachry et al., 2015; Zumbahlen \& Crawley, 1996). Thus, it follows that crawling experience might be related to the development of a preference for angry faces, which was also tested in the present study. Additionally, exploratory analyses were conducted to investigate whether infants' attentional biases were related to differences in how they responded to facial expressions.

\section{Does the Negativity Bias Originate in Infancy?}

Research with young children and adults indicates that they have an attentional bias for negative facial expressions (e.g., Lobue, 2009; Vaish et al., 2008). However, previous research with young infants suggests that this fear bias is not innate. Two studies indicate that infants start out with a preference for happy faces instead. In one study, Farroni, Menon, Rigato, and Johnson (2007) investigated newborn infants' preferences for facial expressions. Preferential looking paradigms are commonly used to assess visual preference in infants. In this type of task, two images are shown side by side on a screen and infant looking time to each image is measured. Typically infants are presented image pairs over multiple trials with side presentation counterbalanced to control for potential side biases. Visual preferences, or biases, are inferred from longer average look durations at certain images over others. In the study by Farroni et al. (2007), newborns were presented with pairs of faces displaying happy, neutral, and fearful expressions in order to assess preference between these expressions. When the newborns 
were shown a fearful and a neutral expression side by side, they did not show a reliable bias for either the fearful or the neutral expression. But when shown a happy versus a fearful expression, newborns spent more time overall looking at the happy face compared to the fearful face. The fact that newborn infants spontaneously prefer happy over fearful faces and do not exhibit a preference for fearful or neutral expressions indicates infants have a preference for happy faces at birth.

A second study, by LaBarbera, Izard, Vietze, and Parisi (1976), provides evidence for a happy preference in infants at around 4 months of age. In this study, infants were shown repeated presentations of three facial expressions (happy, angry, and neutral) presented one at a time. Mean look duration across trials for each expression was calculated. The researchers found that 4-month-old infants looked longer at happy faces when compared to both angry and neutral faces (LaBarbera, Izard, Vietze, \& Parisi, 1976). The results of these two studies illustrate that from birth to 4 months of age, infants do not prefer negative expressions and in fact show a preference for happy faces over other types of facial expressions (i.e., neutral, fearful, and angry).

However, research also shows that infants' preference for happy faces changes starting around 5-6 months of age. This preference for happy expressions is replaced by a strong bias for fearful faces, which emerges between 6-9 months. For example, Peltola, Leppänen, Mäki, and Hietanen (2009) tested infants at 5 and 7 months of age using a preferential looking task. They found that infants at 5 months of age showed no preference for happy or fearful faces, however, infants at 7 months preferred fearful over happy expressions. Other studies using a preferential looking task have found this fear preference is first seen at 6 and 6.5 months (Safar, Kusec, \& Moulson, 2017; Safar \& 
Moulson, 2017).

The fear bias has also been found in studies using paradigms other than preferential looking. Peltola, Leppänen, Palokangas, and Hietanen (2008) used a looking duration task as well as gap/overlap task to assess infant attention to fearful and happy faces at 7 months. Three facial expressions (neutral, happy, fearful) and one control stimulus were randomly presented one time each for 20 seconds and infant look time to each face was recorded. Infants looked longer only at the fearful face more often as compared to the control stimuli. Infants also had the longest fixation times for the fearful face as compared to the control. Looking time and fixation length did not differ between the neutral face, the happy face, and the control stimulus. Immediately following the looking duration task, one of the four stimuli was presented in the center of the screen. After one second, a peripheral target was presented either to the right or the left of the central stimulus. The peripheral target was visible for three seconds. During a gap trial, the center face was removed shortly before the presentation of the target, and on overlap trials the center face remained throughout the trial. In the overlap trials, infants fixated more frequently on the fearful face. Both of these findings indicate an attentional bias towards fearful faces, particularly that fearful faces have the ability to hold 7-month-olds' visual attention.

Several other studies found that fearful faces hold 7-month-old infants' attention more than other emotional facial expressions. Peltola, Leppänen, Vogel-Farley, and Nelson (2009), using a paradigm similar to Peltola et al. (2008), found that it took more time for infants to shift their attention from a central fearful face to a peripheral target stimuli than either a happy, neutral, or neutral face with fearful eyes. Peltola, Hietanen, 
Forssman, and Leppänen (2013) examined attention disengagement probability from facial expressions of emotion in 5-, 7-, and 9-month-old infants using the same gap/overlap task. Disengagement probability was calculated as the proportion of trials with a correct look to the peripheral target out of the total number of trials. They found that disengagement probability decreased after five months, with the 5-month-olds' probability score differing from the 7- and 9-month-olds' score. Disengagement probability was lower (i.e., infants were less likely to look to the target) for fearful expressions in comparison to happy at 7 and 9 months.

Familiarization tasks "familiarize" infants to a certain image by showing repeated presentations of that image. The theory is that once infants are familiar with a certain image, they should prefer to look at a novel image when the familiarized image is presented alongside the novel one. Regardless of the amount of familiarization time, which impacts what infants perceive as familiar and novel, infants still show a bias for fearful expressions. When familiarized to fearful, happy, and neutral faces during rapid presentation ERP trials, 5-month-olds do not show significant differences in looking time during preferential looking trials during the test phase to either fearful or happy faces, suggesting that an attentional preference for either happy or fearful faces is not present at this age. However, 7-month-olds did look longer at test to fearful faces as compared to happy, which again suggests an attentional bias to fearful expressions (Peltola, Leppänen, Mäki, et al., 2009). Nelson, Morse, and Leavitt (1979) familiarized infants to images of two models posing either happy or fearful facial expressions. At test, infants were shown two paired comparison trials of a new model posing both the novel and the familiar expressions. Regardless of which expression was the familiar expression, infants looked 
longer at the fearful expression. From these results it can be seen that infants from 6 to at least 9 months of age clearly show a bias for fearful facial expressions over happy and neutral expressions, regardless of testing paradigm.

An important question that arises out of these findings is whether the bias for fearful faces that emerges around 6 months is specific to fearful expressions alone or reflects a more general bias for negative facial expressions. To examine this, infants' preferences for fearful faces need to be tested directly against another negativelyvalenced expression, such as an angry face. Unfortunately, such a direct test has never been conducted. A majority of infant expression preference studies focus mainly on happy vs. fear. In the few studies that have included angry facial expressions, angry faces were paired with neutral or happy faces but were never directly tested against fearful faces. By 7 months of age, an age when the fear bias has already emerged, happy expressions are still preferred over angry expressions in preferential look tasks (Grossmann, Striano, \& Friederici, 2007; Ichikawa \& Yamaguchi, 2014). At 8 months, however, infants show neither a preference for happy nor a preference for angry facial expressions (Lobue \& DeLoache, 2010). Together the results of these studies suggest that infants' responses to fearful and angry faces may follow different developmental paths. The question of whether infants after 6 months of age have a fear-specific bias or a general negativity bias was addressed in the current study. A preferential-looking task was used to compare 7- to 9-month-old infants' relative looking times to fearful, angry, happy, and neutral faces. 


\section{Is Crawling Experience Related to Infants' Attention to Angry Expressions?}

It is possible that while a fear bias emerges around 6-7 months, an anger preference may not develop until infants begin crawling. The transition from stationary infant to crawling infant is a catalyst for huge changes in infants' emotional environments. The development of autonomous crawling is accompanied by an increase in expressions of anger and frustration by infants, specifically in situations where their goals are impeded (Campos et al., 2000). Caregivers reported an increase in their infant's negative reactivity (Whitney \& Green, 2011) as well as an increase in the frequency and the intensity of their child's angry expressions on a parent interview measure (Campos et al., 1992) as their child began to crawl. In an age held constant design, Chen, Green, \& Gustafson (2009) examined home videos of crawlers and non-crawlers during their normal routine. They found that at 8 months crawling infants were more likely than precrawling infants to vocally protest parental prohibitions. Amount of crawling experience also seems to have an impact on infant anger expression. Using an arm-restraint procedure, Pemberton Roben et al. (2012) found that infants with 6 weeks of crawling experience expressed more anger during arm-restraint than both pre-crawling infants and infants with 2 weeks of crawling experience. Zachry et al. (2015) analyzed videos of infants at daycare, and also found that infant anger increased with crawling experience. The increase in anger occurred after about 1 week of crawling experience and continued to increase after 3 weeks of crawling experience, then began to drop after 6 weeks of experience.

This increase in angry emotionality by the infant ("temper tantrums") and ability to move independently could easily be related to an increase in caregiver frustration and 
anger as well as increased prohibitions by the caregiver to the infant. Caregivers may begin to show an increase in negative expressions in reaction to infants' newfound ability to move independently and to get themselves into potentially dangerous situations. Indeed Campos, Kermoian, and Zumbahlen (1992) found that mothers of 8.5-month-old crawlers "reported [during the parent interview in their study] a sharp increase in their expression of anger toward their infants, stating in many cases that it was the first time in their relationship that they had been angry toward the infant..." (pg. 159). Parents also reported increased expectations of compliance, increased use of verbal prohibitions, and increased use of their voice for discipline. The number of mothers who used prohibitive/ reactive control practices (e.g., using the word 'no,' adjusting tone of voice, using facial expressions to control infant behavior) with their infants increased significantly between mothers of pre-crawling infants and mothers of crawling infants according to parent reported behaviors and a brief observation in the lab (Hendrix \& Thompson, 2011).

In a naturalistic observation study, parents of crawlers were found to use more prohibitions towards their infants than were parents of pre-crawlers (Chen et al., 2009). Another observation-based study looked at changes in parent/infant prohibitive interactions both before and after crawling. Infants and mothers were recorded at home during episodes of naturalistic prohibition when infants were 6 and 8 months old. None of the 6-month-olds were able to crawl, whereas at 8-months some infants had been crawling for about 5 weeks and some remained unable to crawl. Mothers of infants who remained unable to crawl at 8 months showed no changes in amount of negative facial expressions. Mothers of crawling infants showed a significant increase in the amount of 
negative facial expressions during the prohibitive interactions (Zumbahlen \& Crawley, 1996).

From the previously described studies on the impact of crawling on infant and parent emotionality, it can be seen that crawling impacts the infant's emotional environment, with both parent and infant exhibiting more angry behaviors. If emotion expression bias is driven by extensive experience with certain face categories, as other types of face preferences are in infancy (Bar-Haim, Ziv, Lamy, \& Hodes, 2006; Kelly et al., 2005; Quinn, Yahr, Kuhn, Slater, \& Pascalis, 2002; Sugden, Mohamed-Ali, \& Moulson, 2014), then a preference for angry faces may develop in infants who have begun crawling. In the present study, this question was addressed by comparing expression preferences of pre-crawlers and experienced crawlers.

\section{Do Infants' Affective Responses Differ For Fearful and Angry Faces?}

In an exploratory portion of the current study, infants' affective responses to facial expressions were investigated. Affective facial reactions have been studied extensively in adults using the Facial Action Coding System (FACS), which is an anatomically based manual coding system for describing all visually discernible facial movement. It breaks down facial expressions into individual components of muscle movement, called Action Units (AUs) (Ekman \& Friesen, 1978). However, infant faces are different from adult faces. A number of studies have used the Baby FACS system, a FACS emotion coding system specifically designed for typical infant facial configurations (Oster, 2006) to explore affective facial reactions in infants (see Table 1 for a list of AUs have been commonly indicated as related to specifically positive or specifically negative facial displays (Camras et al., 2007; Dondi et al., 2007; Fogel, Hsu, Shapiro, Nelson-Goens, \& 
Secrist, 2006; Kohut, Pillai Riddell, Flora, \& Oster, 2012; Longfier et al., 2016; Mendes

\& Seidl-De-Moura, 2014; Messinger, Cassel, Acosta, Ambadar, \& Cohn, 2008;

Messinger, Mahoor, Chow, \& Cohn, 2009; Soussignan et al., 2017)). Using the Baby

FACS system, researchers have found that infants display a constellation of AUs in response to negative experiences, such as immunization pain (Kohut et al., 2012), novel foods (Longfier et al., 2016), arm restraint, and fear-eliciting situations (Camras et al., 2007).

Table 1

Expression Valence, Facial Behavior Related to that Expression, Action Unit (AU) Number for that Facial Behavior, and Matching Affectiva Metric for the Behavior

\begin{tabular}{llcl}
\hline Valence & Behavior & $\begin{array}{c}\text { Action unit (AU) } \\
\text { number }\end{array}$ & $\begin{array}{c}\text { Affectiva expression } \\
\text { metric }\end{array}$ \\
\hline Positive & Cheek raise & 6 & Cheek raise $^{\text {Smile }}$ \\
\hline Negative & Lip corner raise & 12 & Inner brow raise \\
& Outer brow raise & 1 & Brow raise \\
& Brow knit & 2 & Brow furrow \\
& Brow lowered & 3 & Brow furrow \\
& Nose wrinkle & 4 & Nose wrinkle \\
& Upper lip raise & 9 & Upper lip raise \\
& Nasolabial furrow deepened & 10 & \\
& Lip corners depressed & 11 & Lip corner depressor \\
& Chin raise & 15 & Chin raise \\
& Lips stretched & 17 & Lip stretch \\
& Lips tightened & 20 & \\
& Lips pressed & 23 & \\
\hline Ambiguous & Lips parting & 24 & Lip press \\
& Jaw drop & 25 & Mouth open \\
& Mouth stretch & 26 & Jaw drop \\
\end{tabular}

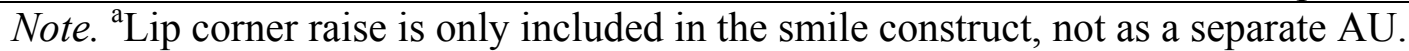


Although the majority of studies using Baby FACS have focused on infants' affective responses to negative situations, one study asked how infants would respond to images of facial expressions. Soussignan et al. (2017) presented 3-, 7-, and 12-month-old infants with virtual models of male and female faces displaying dynamic emotional expressions. Infant expressions were hand-coded using BabyFACS for clusters of AUs representing prototypical expressions and for AUs related to general negative affective responses. Researchers found that while the negative emotional displays did elicit negative AUs, they were not emotion-specific. They also found that while all age groups were able to produce congruent expressions in response to the smiling face, only the 7and 12-month-olds "showed a pattern of responses indicating that they selectively produced positive and negative facial expressions in response to the positive vs. negative facial expressions of the model" (Soussignan et al., 2017, pg. 11). These findings indicate that infants produce valence-appropriate affective responses (i.e., AUs) during the second half of the first year. Their results also show that measuring infant AU responses may be a useful tool in infant emotion perception. In the present study, the effects of viewing different facial expressions on infants' production of AUs were explored.

\section{The Present Study}

In the current study, 7- to 9-month-old infants' attention to fearful, angry, happy, and neutral facial expressions was assessed in a preferential-looking task. Infants were also classified as pre-crawlers or experienced crawlers. Based on previous research showing a robust fear bias in infants in this age group, it was predicted that both experienced crawlers and pre-crawlers at this age would show a bias for fearful over happy and neutral faces, as the fear bias would be unrelated to crawling. However, 
because of the experience hypothesis, it was predicted that infants with crawling experience may prefer angry expressions over happy and neutral ones. Finally, in an exploratory portion of the study, infants' emotional reactions to fearful, happy, angry, and neutral faces were assessed. In particular, I was interested in whether infants would produce similar negative AU reactions to angry and fearful faces or if their affective responses would be unique to fearful faces. I used Affectiva TM (2018), a cutting-edge emotion recognition and analysis platform based on the adult FACS system that codes AUs automatically from video, to code infants' facial reactions when viewing different facial expressions. It is both time and cost-effective to use, relative to the training and use of a manual coding system, such as Baby FACS. This portion of the study was considered exploratory because Affectiva has been validated only in adults and children down to 2 years of age. 


\section{METHODS}

\section{Participants}

Infants aged $6.5-9.5$ months $(N=78)$ were recruited using information provided by the Kentucky Cabinet for Health and Family Services (CHFS) from state birth records and other methods including word of mouth, flyers in the community, and advertisements via the lab's Facebook page. This age group was selected because it included both precrawlers and experienced crawlers. A total of $56\left(M_{\text {age }}=8.03\right.$ months; $S D=.93$; female $=$ 25 , male $=31$ ) healthy, full-term, typically developing infants with normal vision and hearing were included in the final data set. An additional twenty-two infants were tested but excluded from the final data set for the following reasons: parental non-compliance during testing $(n=3)$, failing to complete all portions of the study $(n=3)$, experimenter error $(n=2)$, or not meeting parameters for inclusion. Twelve infants were classified as neither experienced crawlers nor pre-crawlers and two were classified as not developing typically. The final sample included twenty-six pre-crawlers and thirty experienced crawlers (for demographics see Table 2). The racial background of the infants in the final sample was: $90 \%$ White/Non-Hispanic, $8 \%$ biracial, and 2\% Black. 
Table 2

Demographic Characteristics of Infants by Crawling Group

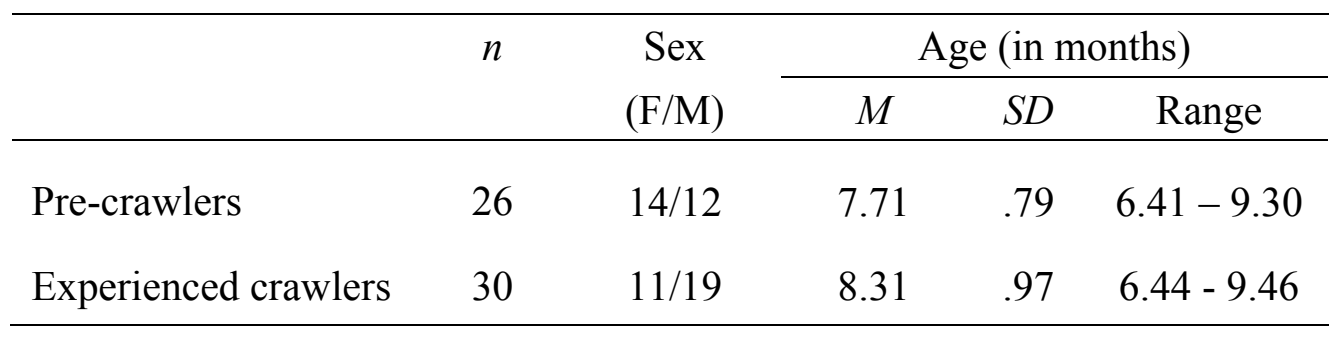

Families in the greater Louisville, KY area who had infants in the desired age range were sent letters or postcards inviting them to participate. If phone numbers were available, families were contacted to answer questions and schedule appointments if interested. Prospective parents could also sign up for more information via our lab's online sign-up form and could request an appointment via email, private messaging on Facebook, or phone. Families received a small gift (i.e., a t-shirt with our lab's logo) as a gift for participating. During the informed consent process, parents were asked questions about their infants' health.

Only infants who were full-term, healthy, typically developing, and had normal vision/hearing were included in the final dataset. Infants were excluded from the final dataset if they demonstrated a side bias of $>.95$ across trials. No infants met this criterion for exclusion. This is commonly used as the definition of side bias in infant research (e.g., Ichikawa \& Yamaguchi, 2014; Safar \& Moulson, 2017). Infants needed to complete all test trials in order to be included in the final dataset. Reliabilities were completed for $20 \%$ of the total sample size, and inter-coder reliability for infant looking times on test trials was $r=.97$. 


\section{Procedure}

\section{Motor development assessment.}

To assess crawling experience, parents completed a motor questionnaire (see Figure 1) where they were asked 1) if their child was crawling on their own and if so 2) how many weeks they had been doing so. Crawling was defined as any independent locomotion (e.g., hands and knees crawling, "bear" crawling, "army" crawling, scooting, rolling, etc.) that allowed infants to reach a desired goal on their own. Crawling was also assessed in lab. A research assistant placed the infant in a crawling position on the carpeted floor of a testing room. The infant's caregiver was 4' away from the infant. The caregiver called the infant and offered a toy to encourage movement to the caregiver. The infant should be able to reach their parent if they were able to crawl. The purpose of this assessment was to confirm the parental report of the infant's ability to crawl.

Based on the questionnaire and the in-lab assessment, infants were classified as either 1- pre-crawler (unable to crawl on own), 2- new crawler (able to crawl on own but only has a maximum of 2 weeks crawling experience), 3 - crawler (able to crawl and has between 3-4 weeks of crawling experience) and 4- experienced crawler (able to crawl on own and has 4 or more weeks of crawling experience). Experienced crawlers have been typically defined as having at least four weeks of crawling experience and differences have been found between infants that are unable to crawl and experienced crawlers (Campos et al., 1992; Pemberton Roben et al., 2012; Ueno, Uchiyama, Campos, Dahl, \& Anderson, 2012; Zachry et al., 2015; Zumbahlen \& Crawley, 1996). If crawling ability in the lab did not match parent-reported crawling, parents were asked additional questions to further clarify their child's crawling ability/experience. Infants categorized as new 
crawlers or crawlers were not analyzed for this study. During the scheduling process, caregivers were asked if their child was able to crawl and if so, for how long they had been crawling. This made it possible for us to schedule infants when they were unable to crawl, and when they had been crawling for 4+ weeks.

\begin{tabular}{|c|c|c|c|}
\hline Motor Milestones & Yes & No & How long (weeks)? \\
\hline $\begin{array}{l}\text { 1. Sitting on his/her } \\
\text { own? }\end{array}$ & Yes & No & \\
\hline $\begin{array}{l}\text { 2. Crawling on his/her } \\
\text { own? }\end{array}$ & Yes & No & \\
\hline $\begin{array}{l}\text { 3. Pulling up on his/her } \\
\text { own? }\end{array}$ & Yes & No & \\
\hline $\begin{array}{l}\text { 4. Creeping/cruising on } \\
\text { his/her own? }\end{array}$ & Yes & No & \\
\hline $\begin{array}{l}\text { 5. Standing on his/her } \\
\text { own? }\end{array}$ & Yes & No & \\
\hline $\begin{array}{l}\text { 6. Walking on his/her } \\
\text { own? }\end{array}$ & Yes & No & \\
\hline
\end{tabular}

Figure 1. Motor development questionnaire filled out by infant's caregiver.

\section{Affective response and emotion bias tasks.}

Stimuli. The stimuli for the affective response task were four different images, singly presented on 4 trials, of the same woman posing four different facial expressions (happy, neutral, angry, and fearful). The order of these four faces was randomized across participants. Each face is $21 \times 19.5^{\prime}$ as measured on the screen, and subtended $23.45^{\circ} \mathrm{x}$ $21.82^{\circ}$ of visual angle on the screen. The face stimuli came from the NimStim database, a collection of static images of real pictures of people making various expressions (Tottenham et al., 2009). The faces used are female faces \#01, \#10, \#12, \#13, \#15, and \#19. Three different stimulus sets were created, each with two models displaying all four expressions, for the African America, Asian, and Caucasian faces. The set used with each 
participant was chosen to match the racial identity of the primary caregiver, as other-race effects can impact emotion preference (e.g., Safar et al., 2017).

The stimuli for the emotion bias phase consisted of pairs of images of the same woman posing two different facial expressions (happy vs. neutral, happy vs. angry, happy vs. fearful, angry vs. fearful, angry vs. neutral, and fearful vs. neutral). The sides of these expressions were counterbalanced for a total of 12 expression pairs. Each face in the pair measured $15 \times 13.75$ " on the screen with 8 " of space between them. Each face in this phase subtended $16.06^{\circ} \times 15.21^{\circ}$ of visual angle on the screen (white space subtended $9.04^{\circ} \times 16.87^{\circ}$ of visual angle on the screen). Two different models were used so that each infant sees a different face identity for the affective response and emotion bias tasks. Which model was used in which phase was counterbalanced across participants.

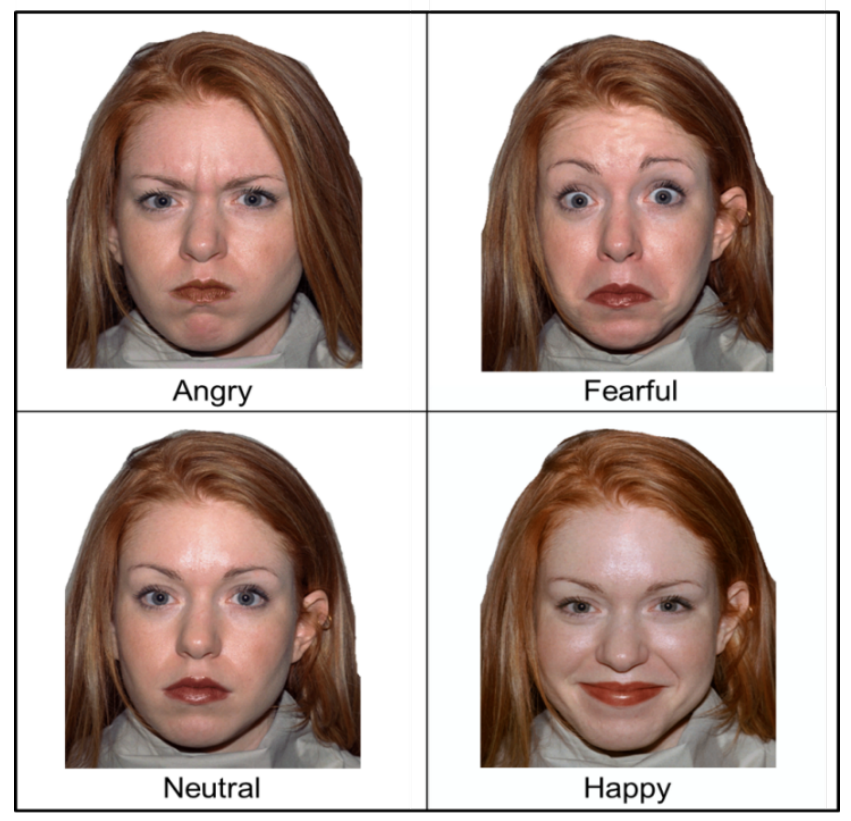

Figure 2. Example face stimulus set displaying angry, fearful, neutral, and happy expressions. Model \#01 from the NimStim database of facial expressions. 


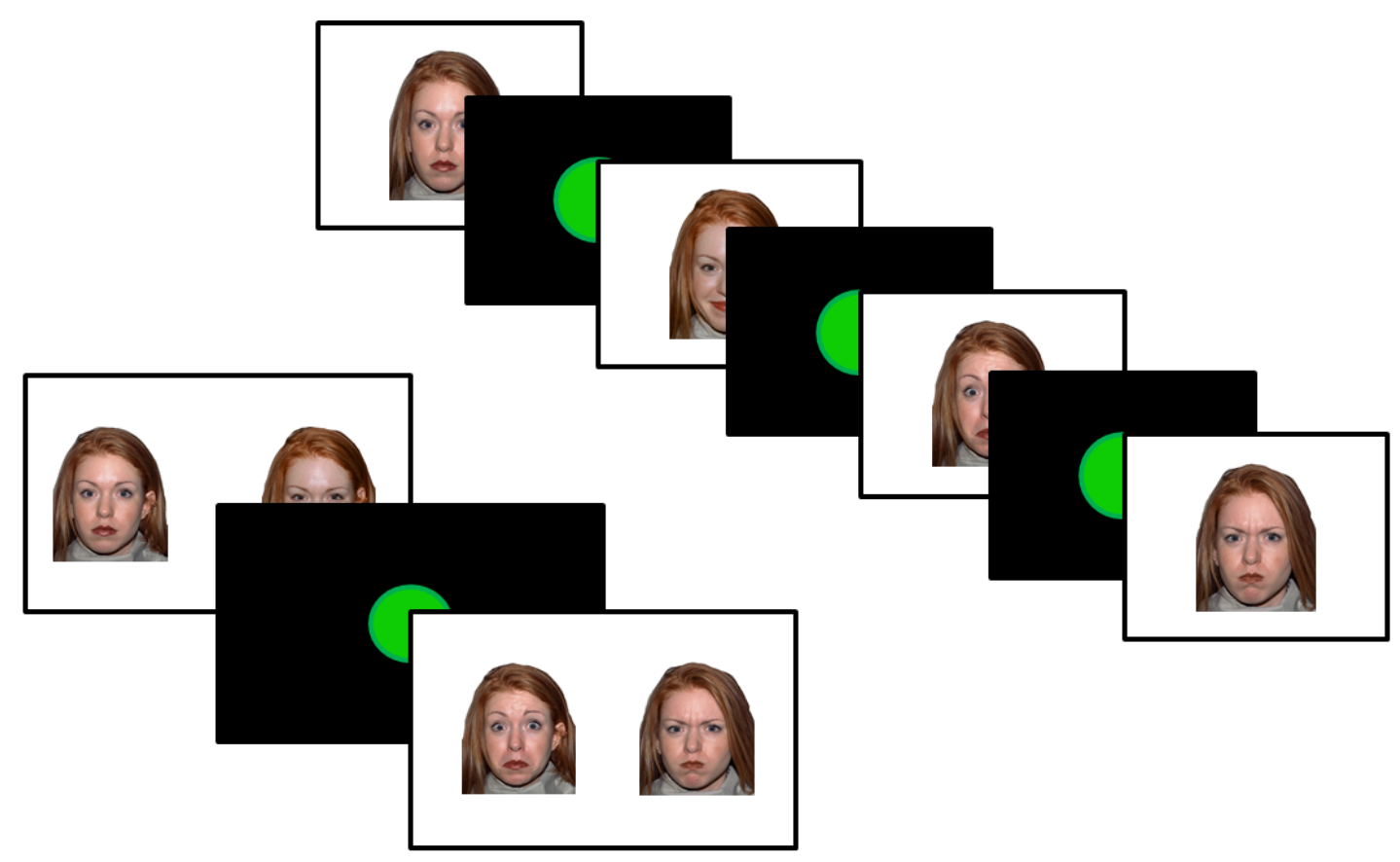

Figure 3. Top right: Example of stimuli presented on trials in affective response task. Bottom left: Example of stimuli on trials in preferential looking task.

Apparatus. During both the emotion bias and affective response tasks, infants were seated on a parent's lap approximately 50" away from a high-definition plasma TV (screen size $45 \times 25.5$ ") that displayed the stimuli for both tasks. To avoid distracting the infant, the light in experiment room was dimmed. This room is also sound attenuated to prevent outside noise interference. An experimenter observed infants during the experiment on a 15 " JVC closed circuit monitor that displayed live video of the infant from a Canon VCC50i camera situated under the stimulus display. Stimuli were presented using Habit 2 (v2.1.25) software (Oakes, Sperka, \& Cantrell, 2015) from a MacPro desktop. At the beginning of each task an attention-getting video played. The attention getter (AG) consisted of a bright green circle, which grew larger and smaller on 
the black background, creating a looming effect. It was accompanied by a bell-like ringing sound.

Procedure. After completing the motor development assessment, infants participated in the affective response and the emotion bias tasks. The order of these latter two tasks was counterbalanced across participants. Infants were randomly assigned to one of the 24 orders. There was a short break in between the two tasks to allow for setup of the next phase of the study. Parents were asked not to interact with their infants during the experiment in order to avoid distraction. Experimenters were blind to the stimuli order for both phases. Video of the infant's face and looking behavior was recorded for later coding.

Emotion bias task. When the infant attended to the screen, the experimenter pressed the "return" key to initiate stimulus presentation. The AG played prior to each trial stimulus to recapture infant attention. Each expression (happy, angry, neutral, and fearful) was paired with one of the other three expressions resulting in 6 different expression pairs per model (see Figure 2). The first six trials made up block one and the last six made up block two. All six emotion pairs were presented in the first block, and the second block consisted of these same six pairs with their positions switched for counterbalancing purposes. For example, if a participant saw the fearful vs. happy trial in block one with the fearful face presented on the left side of the screen then the fearful face would be presented on the right side of the screen in the fearful vs. happy trial in block two. Trial times for the emotion bias phase were a fixed length of 10 seconds each, which is a standard amount of time for preferential looking trials. 
Affective response task. Similar to the emotion bias phase, when the infant was attending to the screen, the experimenter began stimulus presentation and the AG played to engage the infant's attention toward the monitor. Each expression (happy, angry,

neutral, and fearful) was presented by itself, once, for a total of 4 test trials (see Figure 3). Each trial had a fixed length of 20 seconds.

\section{Video Coding}

Emotional bias task. The direction of infants' visual attention (left or right) during each trial was coded frame by frame offline using Datavyu (Datavyu Team, 2014) by research assistants who were blind to the expressions infants viewed on each trial. Looking time for each expression in each pair and total look time to the pair overall was averaged between the two blocks, except in the case when an infant looked less than a second to a trial. Trials where an infant looked less than one second were left out of the analysis. Only five infants looked for less than a second during a trial, and of these five, only one infant looked for less than a second on more than one trial. In these cases, only the look times from the corresponding block one expression pair were used.

Affective response. Videos from the affective response task were analyzed by Affectiva's "Emotion as a Service" program. Affectiva detects both very large and very subtle (undetectable by the human eye) muscle movements in videos of faces and tracks the intensity of AU production over time. It provides an intensity score (a value of 0-100) per AU at a rate of about 30 samples per second (see Figure 4). Each sample had metrics for 7 emotions (anger, sadness, disgust, joy, surprise, fear, and contempt) and 20 AUs.

Matlab and R code were used to clean and organize the data in preparation for an exploration of infants' average intensity of AUs over time to facial expressions. Due to 
the amount of time points across trials, the data were binned into four time segments $(0-5$, 5.001-10, 10.001-15, and 15.001-20 seconds). Intensity scores were averaged within each time bin for each baby for each of the nine AUs. Mean negative AU intensity score at each time bin was calculated by averaging the nine AU intensity scores together.

The amount of good data per participant (bad data occurred when the program was unable to detect the infant's face or when the infant was not looking at the screen) was calculated by dividing the useable number of samples of data by the total number of possible samples during the four test trials. On average, $60 \%$ of the data was usable (Mdn $=60 \%$, range $=25 \%-97 \%)$ and about 1,520 samples $(M d n=1,458$, range $=590-3,419)$ were produced per infant. No infants' data were omitted for not providing a high enough percentage of good data.

\begin{tabular}{|c|c|c|c|c|c|c|c|c|c|c|c|c|c|c|c|}
\hline 4 & A & B & c & & D & E & $\mathrm{F}$ & G & H & 1 & J & $k$ & L & M & $\mathrm{N}$ \\
\hline 1 & time stamp (msec) & face id & anger & & contempt & disgust & engagement & fear & joy & sadness & surprise & valence & attention & inner brow raise & brow raise \\
\hline 2 & 9.04 & & 1 & 0.01 & 0.19 & 0.83 & 1.13 & 0.00 & 0.00 & 0.01 & 0.50 & 0.00 & 78.35 & 0.02 & 0.55 \\
\hline 3 & 9.08 & & 1 & 0.01 & 0.19 & 1.06 & 4.28 & 0.00 & 0.00 & 0.00 & 0.91 & 0.00 & 88.01 & 0.03 & 5.82 \\
\hline 4 & 9.11 & & 1 & 0.00 & 0.19 & 1.59 & 73.82 & 0.00 & 0.00 & 0.00 & 8.79 & 0.00 & 94.59 & 0.05 & 41.56 \\
\hline 5 & 9.14 & & 1 & 0.00 & 0.19 & 2.24 & 99.01 & 0.00 & 0.00 & 0.00 & 41.90 & 0.00 & 90.86 & 0.14 & 72.00 \\
\hline 6 & 9.18 & & 1 & 0.00 & 0.19 & 2.48 & 99.52 & 0.00 & 0.00 & 0.00 & 54.65 & 0.00 & 92.16 & 0.16 & 76.57 \\
\hline 7 & 9.21 & & 1 & 0.00 & 0.19 & 2.51 & 99.23 & 0.01 & 0.00 & 0.00 & 48.65 & 0.00 & 96.90 & 0.07 & 69.22 \\
\hline 8 & 9.24 & & 1 & 0.00 & 0.19 & 2.52 & 99.54 & 0.00 & 0.00 & 0.00 & 55.64 & 0.00 & 95.65 & 0.03 & 76.28 \\
\hline 9 & 9.28 & & 1 & 0.00 & 0.19 & 2.53 & 99.66 & 0.00 & 0.00 & 0.00 & 60.43 & 0.00 & 94.36 & 0.02 & 80.33 \\
\hline 10 & 9.31 & & 1 & 0.00 & 0.19 & 2.54 & 99.42 & 0.00 & 0.00 & 0.00 & 50.78 & 0.00 & 98.37 & 0.01 & 72.59 \\
\hline 11 & 9.34 & & 1 & 0.00 & 0.19 & 2.55 & 99.24 & 0.00 & 0.00 & 0.00 & 46.53 & 0.00 & 98.31 & 0.01 & 68.58 \\
\hline 12 & 9.38 & & 1 & 0.00 & 0.19 & 2.55 & 99.44 & 0.00 & 0.00 & 0.00 & 51.90 & 0.00 & 94.58 & 0.01 & 73.03 \\
\hline 13 & 9.41 & & 1 & 0.00 & 0.19 & 2.53 & 98.89 & 0.00 & 0.00 & 0.00 & 40.14 & 0.00 & 94.58 & 0.01 & 63.66 \\
\hline 14 & 9.44 & & 1 & 0.00 & 0.19 & 2.53 & 98.74 & 0.00 & 0.00 & 0.00 & 38.46 & 0.00 & 92.45 & 0.00 & 61.92 \\
\hline 15 & 9.48 & & 1 & 0.00 & 0.19 & 2.52 & 99.10 & 0.00 & 0.00 & 0.00 & 44.21 & 0.00 & 94.13 & 0.00 & 66.81 \\
\hline 16 & 9.51 & & 1 & 0.00 & 0.19 & 2.51 & 99.78 & 0.00 & 0.00 & 0.00 & 68.35 & 0.00 & 96.07 & 0.00 & 86.86 \\
\hline
\end{tabular}

Figure 4. Example of raw Affectiva output. 


\section{RESULTS}

\section{Emotion Bias and Crawling Experience}

Preliminary analyses indicated that there were no significant effects of age, sex, or stimulus set (i.e., which model infants saw) on emotion bias, so these variables were excluded from all subsequent analyses.

Infants' mean looking times to each expression per pair are shown in Figure 5 and Table 3. To test the hypothesis that the fear bias is specific to fear, and to investigate the role of crawling in infants' preferences, six separate 2 (expression: expression \#1, expression \#2) X 2 (crawling status: pre-crawlers, experienced crawlers) mixed model ANOVAs were performed, one for each expression pair. Expression was a withinsubjects variable. No main or interaction effects with crawling were found in any of the ANOVAs (all $p \mathrm{~s}>.05$, see Table 4 for interaction statistics). However, statistically significant main effects of expression were found for the three ANOVAs involving fearful faces. Infants looked significantly longer at the fearful expression when paired with the angry, $F(1,54)=19.06, p<.001, \mathrm{n}_{\mathrm{p}}^{2}=.26$, happy $F(1,54)=4.93, p=.03, \mathrm{n}_{\mathrm{p}}{ }^{2}=$ .08 , and neutral, $F(1,54)=6.03, p=.02, \mathrm{n}_{\mathrm{p}}{ }^{2}=.10$, expressions. There was not a significant main effect for the angry/happy pair, $F(1,54)=.31, p=.58$, the happy/neutral pair, $F(1,54)=3.50, p=.07$, or the angry/neutral pair, $F(1,54)=.22, p=.64$. These results indicate that fear was preferred over angry, happy, and neutral expressions and that no other preferences were seen between any of the other expressions. 


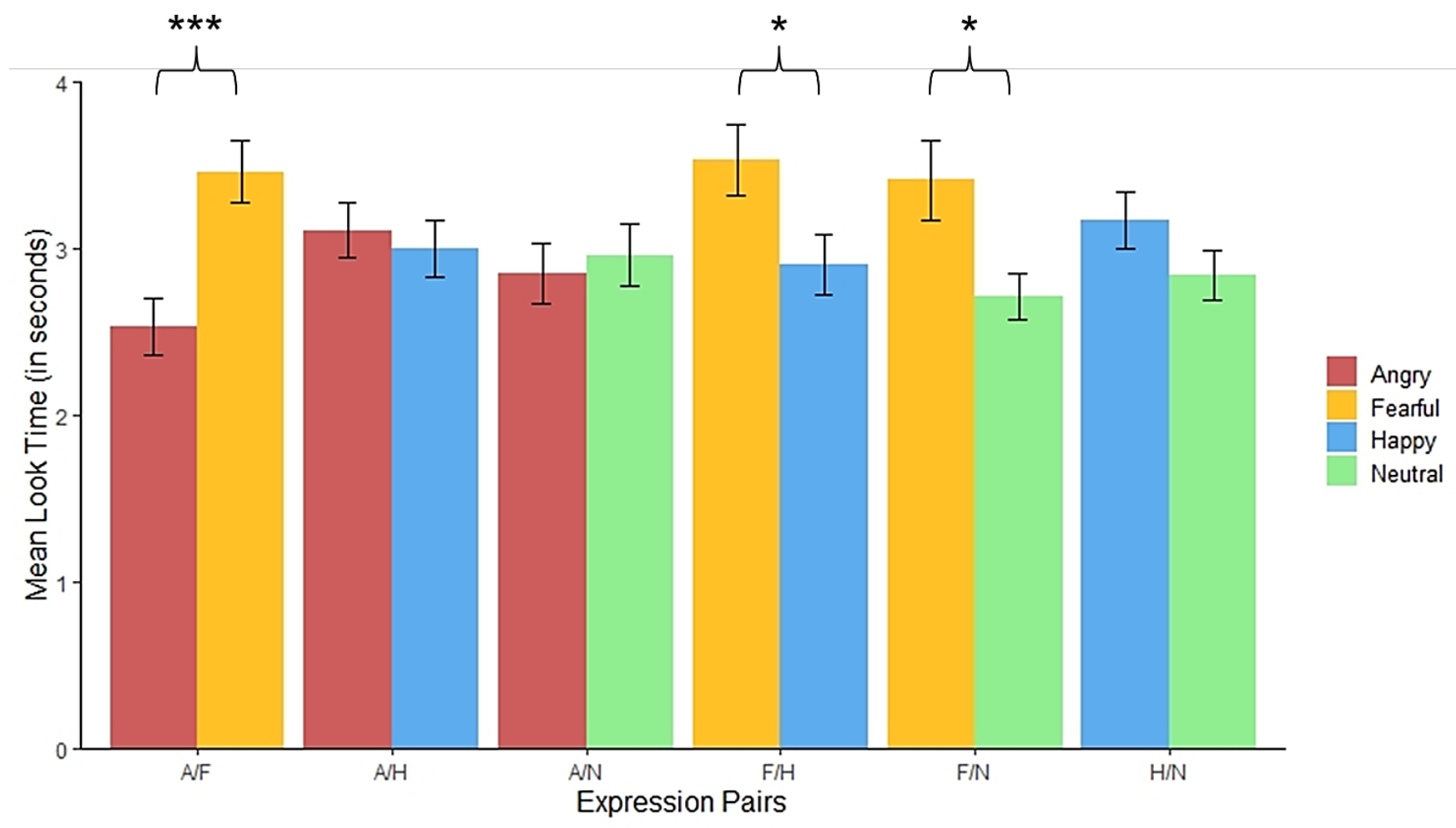

Figure 5. Infants' mean looking time to each facial expression per pair during emotion bias test trials. Separate ANOVAs were conducted for each emotion pair. Statistically significant main effects for expression are indicated with asterisks. Error bars represent standard error of the mean.

${ }^{*} p<.05,{ }^{* * *} p<.001$ 
Table 3

Infants' Mean (SD) Look Times (in seconds) to Each Expression per Expression Pair during Emotion Bias Test Trials

\begin{tabular}{lll}
\hline Expression Pair & Expression & Mean $(S D)$ \\
\hline Angry/Fearful & Angry & $2.54(1.26)$ \\
& Fearful & $3.46(1.43)$ \\
Angry/Happy & Angry & $3.10(1.26)$ \\
& Happy & $3.01(1.29)$ \\
\hline Angry/Neutral & Angry & $2.86(1.30)$ \\
& Neutral & $2.95(1.40)$ \\
\hline \multirow{3}{*}{ Fearful/Happy } & Fearful & $3.51(1.55)$ \\
& Happy & $2.91(1.36)$ \\
Fearful/Neutral & Fearful & $3.41(1.79)$ \\
& Neutral & $2.71(1.05)$ \\
Happy/Neutral & Happy & $3.18(1.26)$ \\
& Neutral & $2.83(1.09)$ \\
\hline
\end{tabular}

Table 4

F-statistics, p-values, Effect Sizes, and Observed Power Values for Non-Significant Interactions in the 6, 2(Expression) X 2(Crawling Status) ANOVAs

\begin{tabular}{lllll}
\hline $\begin{array}{l}\text { Expression Pair } \\
\text { X Crawling }\end{array}$ & F-statistic & P-value & $\mathrm{n}_{\mathrm{p}}{ }^{2}$ & Observed Power \\
\hline Angry/Fear & $F(1,54)=.91$ & .40 & .01 & .13 \\
\hline Happy/Angry & $F(1,54)=3.58$ & .06 & .06 & .46 \\
\hline Happy/Neutral & $F(1,54)=3.06$ & .09 & .05 & .41 \\
\hline Happy/Fearful & $F(1,54)=1.75$ & .19 & .03 & .26 \\
\hline Fearful/Neutral & $F(1,54)=.14$ & .71 & .003 & .07 \\
\hline Angry/Neutral & $F(1,54)=1.10$ & .30 & .02 & .18 \\
\hline
\end{tabular}




\section{Infants' Affective Responses}

Mean negative AU intensity produced by infants when viewing each of the four expressions is presented in Table 5. To explore whether infants produced similar reactions to angry and fearful faces or responded uniquely to fearful faces, an ANOVA was conducted with planned comparisons to specifically examine mean negative intensity to the fearful face compared to the other three expressions. Data from 21 of the 56 infants were excluded from this analysis due to their not having intensity data for all four time bins. The decision was made to not include crawling in this analysis due to missing data. Inclusion of this variable with the remaining data would have resulted in drastically uneven sample sizes.

A 4 (time bin: 1, 2, 3, 4) X 4 (expression: fearful, angry, happy, neutral) repeated measures ANOVA was conducted on mean negative AU intensity. The ANOVA revealed no significant main effect of expression, $F(3,102)=1.56, p=.20, n_{p}{ }^{2}=.04$, or time bin $F(3,102)=.53, p=.66, \mathrm{n}_{\mathrm{p}}{ }^{2}=.02$. The interaction between expression and time bin was not significant either, $F(9,306)=.43, p=.92, \mathrm{n}_{\mathrm{p}}{ }^{2}=.01$. However, planned comparison paired-sample t-tests revealed that the intensity of infants' reactions was significantly greater for the fearful versus the angry face, $t(55)=2.42, p=.019, d=.37$. Intensity for the fearful face was not significantly different from those of the happy, $t(55)=.57, p=$ $.57, d=.08$, or neutral faces, $t(55)=.86, p=.39, d=.12$. 
Table 5

Mean Negative AU Intensity per Expression during the Affective Response Task

\begin{tabular}{ll}
\hline Expression & Mean $(S D)$ \\
\hline Fearful & $5.50(3.09)$ \\
Angry & $4.47(2.50)$ \\
Happy & $5.27(2.81)$ \\
Neutral & $5.13(3.07)$ \\
\hline
\end{tabular}




\section{DISCUSSION}

In the current study, 7- to 9-month-old infants' visual preferences and affective reactions toward fearful, angry, neutral, and happy facial expressions were investigated. The first main finding was that infants showed a reliable preference for fearful over angry, neutral, and happy expressions in the preferential looking task. Second, no evidence was found for an angry preference or an effect of crawling on infants' expression preferences. Third, in the exploratory portion of the study using Affectiva, infant negative affective response was found to be more intense for the fearful face relative to the angry face.

Previous findings show that the attentional bias to fearful over happy or neutral faces develops around 6-7 months of age and continues until possibly the end of the first year of life (de Haan, Belsky, Reid, Volein, \& Johnson, 2004; Leppänen, Moulson, Vogel-Farley, \& Nelson, 2007; Nelson \& Dolgin, 1985; Peltola et al., 2011, 2008; Peltola, Leppänen, Mäki, et al., 2009; Peltola, Leppänen, Vogel-Farley, et al., 2009; Safar et al., 2017; Safar \& Moulson, 2017). The results from the current study replicate these previous findings and extend them to show that infants in this age range also prefer fearful over angry faces. It remains to be seen if infants do display an anger preference at some point during the $1^{\text {st }}$ year of life. Future research should examine infant preference for angry facial expressions from 9 months into toddlerhood.

The present study also examined whether or not crawling experience may be related to a possible emergence of an angry preference. Researchers have reasoned that 
through crawling, infants elicit more negative reactions from their caregivers and display more negative behaviors themselves, which in turn impacts the general emotional environment of the infant. This change in the environment then influences infant emotion preference, namely a preference for angry expressions. However, the results of the current study suggest that the development of crawling is not related to infant bias for angry facial expressions. In addition to the fact that an angry preference was not found in this study, no evidence of an effect of crawling on infants' expression preferences was found either. One possible explanation for this result is that the overall change in the emotional environment that occurs with the onset of crawling is not extreme enough to produce an anger preference. Other studies on infant face preferences show that their preferences are driven by extensive experience. For example, infants for the most part prefer female, own-race, and adult-aged faces. Indeed, Sugden et al. (2014), using small head cameras on infants to record their daily visual experiences, found that the faces 1 - to 3-month-old infants saw in their day-to-day lives were primarily own-race (96\%), adultage $(81 \%)$, and female $(70 \%)$. Future research should implement this method of assessing infants' everyday visual input to facial expressions as they learn to crawl. The use of headcam technology could shed light on whether infants' visual exposure to angry facial expressions truly increases once crawling begins.

Finally, in the exploratory portion of this study that focused on infants' affective reactions to facial expressions, mean intensity for negative AUs was found to be higher for the fearful face relative to the angry face, however, differences on mean negative AU intensity were not found between fearful and happy or fearful and neutral expressions. The overall pattern of results on this task differs from that of the attentional bias task in 
that a difference was found between the fearful face and all three other facial expressions in the attentional bias task, whereas a difference was found between only fear and angry in the affective reaction task. The pattern that is suggested from these two sets of results is that infants react differently to fearful and angry faces in terms of both visual attention and affective response. However, the present result regarding infants' affective responses to fearful and angry faces is tentative as this study is the first to incorporate Affectiva with infants, which has not been validated with this age group. These results should be replicated before strong conclusions can be drawn.

Still, the present affective response findings suggest that there may be promise for using Affectiva in research with infants. As a reminder, Affectiva intensity scores have a range of $0-100$, and the cutoff for intensity that indicates movement large enough to be detected by the human eye is an intensity score of greater than 20 . However, the fact that Affectiva can reveal responses that fall below threshold for human coders (as in the current study) indicates that Affectiva could be an asset and become a useful tool for infant researchers in the future. Mean intensity of AUs was examined in this study, but other metrics such as peak intensity, latency to peak intensity, minimum and maximum intensities, as well as time-series analyses could also be useful. Large scale studies examining individual differences on these metrics would also be informative.

\section{Limitations}

This study did not address other sources of variability that have been shown to impact infant emotional biases. New research suggests that infant temperament can effect attention latency and dwell time to negative displays of emotion (Pérez-Edgar et al., 2017). In addition, research has shown that maternal positive affect is related to infants 
looking longer to a fearful expression at 7 months as compared to a happy expression (e.g. de Haan et al., 2004). Future work should examine individual differences in infant emotion bias.

Even though this is one of the only studies to examine emotion preference using multiple pairings of expressions within the same age group, not all emotions were investigated in this study. Preference for other negative emotions, such as disgust, sadness, and surprise, were not examined in the current study. The particular expressions included in this study were chosen for methodological reasons as well as theoretical ones. Adding an additional three expressions into the study would have increased the number of expression pairings from 6 to 21 and would have increased the number of test trials from 12 to 42 . The length of testing time would have increased from 2 minutes to 7 minutes, and there were concerns about infants' ability to pay attention to static pictures for that length of time. Also, the research on bias for typically developing infants for these three expressions is very limited, so hypotheses about how infants would respond to these expressions could not be created. In addition, the stimuli used for this study are not naturalistic displays of emotion. Most studies on emotion preference have used static expressions, which is why the current study does as well, but it would also be worth investigating if infants would respond in the same way to more naturalistic displays of emotion (e.g., dynamic displays of emotion, subtle expressions, or contingent expression response).

Lastly, efforts were made to recruit broadly in the metro area, and diverse stimulus sets were created so that the race of the stimuli would match that of the infant's primary caregiver. However, as is unfortunately common in psychological research 
(Henrich, Heine, \& Norenzayan, 2010), the sample for this study consisted of WEIRD (Western, Educated, Industrialized, Rich, and Democratic) participants, that is, $90 \%$ of the current sample was White/Non-Hispanic. Therefore, the results of this study may not be generalizable. Future research should examine infant emotion bias with diverse samples.

\section{Conclusion}

The results from the current study answer an important question about the development of the negativity bias. In infancy, the fear bias observed around 6-9 months of age is not a general negativity bias but rather a bias that is specific to fearful faces alone. This study's findings also provide evidence that crawling is unrelated to expression bias in this age range. These findings allow for future research to examine other underlying mechanisms that account for infants' happy bias changing into a fear bias. This is also the first study to examine infants' affective responses to facial expressions while using Affectiva, a computer-based coding system. While the Affectiva portion of this study was exploratory, the results demonstrate that this automated coding system has potential as a novel method that could be utilized to easily and quickly measure infants' affective reactions. 


\section{REFERENCES}

Adolph, K. E., Vereijken, B., \& Denny, M. A. (1998). Learning to crawl. Child Development, 69(5), 1299-1312.

Bar-Haim, Y., Ziv, T., Lamy, D., \& Hodes, R. M. (2006). Nature and nurture in own-race face processing. Psychological Science, 17(2), 159-163. https://doi.org/10.1111/j.1467-9280.2006.01679.x

Campos, J. J., Anderson, D. I., Barbu-Roth, M. A., Hubbard, E. M., Hertenstein, M. J., \& Witherington, D. (2000). Travel broadens the mind. Infancy, 1(2), 149-219. https://doi.org/10.1207/S15327078IN0102_1

Campos, J. J., Kermoian, R., \& Zumbahlen, M. R. (1992). Socioemotional transformations in the family system following infant crawling onset. In New Directions for Child and Adolescent Development (Vol. 55, pp. 25-40). https://doi.org/10.1002/cd.23219925504

Camras, L. a., Oster, H., Bakeman, R., Meng, Z., Ujiie, T., \& Campos, J. J. (2007). Do infants show distinct negative facial expressions for fear and anger? Emotional expression in 11-month-old European American, Chinese, and Japanese infants. Infancy, 11(2), 131-155. https://doi.org/10.1111/j.1532-7078.2007.tb00219.x

Chen, X., Green, J. A., \& Gustafson, G. E. (2009). Development of vocal protests from 3 
to 18 months. Infancy, 14(1), 44-59. https://doi.org/10.1080/15250000802569694

de Haan, M., Belsky, J., Reid, V., Volein, A., \& Johnson, M. H. (2004). Maternal personality and infants' neural and visual responsivity to facial expressions of emotion. Journal of Child Psychology and Psychiatry, 45(7), 1209-1218. https://doi.org/10.1111/j.1469-7610.2004.00320.x

Dondi, M., Messinger, D., Colle, M., Tabasso, A., Simion, F., Barba, B. D., \& Fogel, A. (2007). A new perspective on neonatal smiling: Differences between the judgments of expert coders and naive observers. Infancy, 12(3), 235-255. https://doi.org/10.1111/j.1532-7078.2007.tb00242.x

Fogel, A., Hsu, H.-C., Shapiro, A. F., Nelson-Goens, G. C., \& Secrist, C. (2006). Effects of normal and perturbed social play on the duration and amplitude of different types of infant smiles. Developmental Psychology, 42(3), 459-473. https://doi.org/10.1037/0012-1649.42.3.459

Grossmann, T., Striano, T., \& Friederici, A. D. (2007). Developmental changes in infants' processing of happy and angry facial expressions: A neurobehavioral study. Brain and Cognition, 64(1), 30-41. https://doi.org/10.1016/j.bandc.2006.10.002

Heck, A., Hock, A., White, H., Jubran, R., \& Bhatt, R. S. (2016). The development of attention to dynamic facial emotions. Journal of Experimental Child Psychology, 147, 100-110. https://doi.org/10.1016/j.jecp.2016.03.005

Hendrix, R. R., \& Thompson, R. A. (2011). Development of self-produced locomotion in the first year: Changes in parent perceptions and infant behaviour. Infant and Child 
Development, 20, 288-300. https://doi.org/10.1002/icd

Henrich, J., Heine, S. J., \& Norenzayan, A. (2010). The weirdest people in the world? Behavioral and Brain Sciences, 33(2-3), 61-83. https://doi.org/10.1017/S0140525X0999152X

Ichikawa, H., \& Yamaguchi, M. K. (2014). Infants' recognition of subtle anger facial expression. Japanese Psychological Research, 56(1), 15-23. https://doi.org/10.1111/jpr.12025

Kelly, D. J., Quinn, P. C., Slater, A. M., Lee, K., Gibson, A., Smith, M., ... Pascalis, O. (2005). Three-month-olds, but not newborns, prefer own-race faces. Developmental Science, 8(6). https://doi.org/10.1111/j.1467-7687.2005.0434a.x.Three-month-olds

Kohut, S. A., Pillai Riddell, R., Flora, D. B., \& Oster, H. (2012). A longitudinal analysis of the development of infant facial expressions in response to acute pain: Immediate and regulatory expressions. Pain, 153(12), 2458-2465. https://doi.org/10.1016/j.pain.2012.09.005

Leppänen, J. M., Cataldo, J. K., Enlow, M. B., \& Nelson, C. A. (2018). Early development of attention to threat-related facial expressions. PLoS ONE, 13(5), 113. https://doi.org/10.1371/journal.pone.0197424

Leppänen, J. M., Moulson, M. C., Vogel-Farley, V. K., \& Nelson, C. A. (2007). An ERP study of emotional face processing in the adult and infant brain. Child Development, 78(1), 232-245. https://doi.org/10.1111/j.1467-8624.2007.00994.x

Lobue, V. (2009). More than just another face in the crowd: Superior detection of 
threatening facial expressions in children and adults. Developmental Science, 12(2), 305-313. https://doi.org/10.1111/j.1467-7687.2008.00767.x

Lobue, V., \& DeLoache, J. S. (2010). Superior detection of threat-relevant stimuli in infancy. Developmental Science, 13(1), 221-228. https://doi.org/10.1111/j.14677687.2009.00872.x

Longfier, L., Soussignan, R., Reissland, N., Leconte, M., Marret, S., Schaal, B., \& Mellier, D. (2016). Emotional expressiveness of 5-6 month-old infants born very premature versus full-term at initial exposure to weaning foods. Appetite, 107, 494500. https://doi.org/10.1016/j.appet.2016.08.124

Mendes, D. M. L. F., \& Seidl-De-Moura, M. L. (2014). Different kinds of infants' smiles in the first six months and contingency to maternal affective behavior. Spanish Journal of Psychology, 17(2). https://doi.org/10.1017/sjp.2014.86

Messinger, D. S., Cassel, T. D., Acosta, S. I., Ambadar, Z., \& Cohn, J. F. (2008). Infant smiling dynamics and perceived positive emotion. Journal of Nonverbal Behavior, 32(3), 133-155. https://doi.org/10.1007/s10919-008-0048-8

Messinger, D. S., Mahoor, M. H., Chow, S. M., \& Cohn, J. F. (2009). Automated measurement of facial expression in infant - mother interaction: A pilot study. Infancy, 14(3), 285-305. https://doi.org/10.1080/15250000902839963

Nelson, C. A., \& Dolgin, K. G. (1985). The generalized discrimination of facial expressions by seven-month-old infants. Child Development, 56(1), 58-61.

Nelson, C. A., Morse, P. A., \& Leavitt, L. A. (1979). Recognition of facial expressions 
by seven-month-old infants. Child Development, 50, 1239-1242.

Peltola, M. J., Hietanen, J., Forssman, L., \& Leppänen, J. M. (2013). The emergence and stability of the attentional bias to fearful faces in infancy. Infancy, 18(6), 905-926. https://doi.org/10.1111/infa.12013

Peltola, M. J., Leppänen, J. M., \& Hietanen, J. K. (2011). Enhanced cardiac and attentional responding to fearful faces in 7-month-old infants. Psychophysiology, 48(9), 1291-1298. https://doi.org/10.1111/j.1469-8986.2011.01188.x

Peltola, M. J., Leppänen, J. M., Mäki, S., \& Hietanen, J. K. (2009). Emergence of enhanced attention to fearful faces between 5 and 7 months of age. Social Cognitive and Affective Neuroscience, 4(2), 134-142. https://doi.org/10.1093/scan/nsn046

Peltola, M. J., Leppänen, J. M., Palokangas, T., \& Hietanen, J. K. (2008). Fearful faces modulate looking duration and attention disengagement in 7-month-old infants. Developmental Science, 11(1), 60-68. https://doi.org/10.1111/j.14677687.2007.00659.x

Peltola, M. J., Leppänen, J. M., Vogel-Farley, V. K., \& Nelson, C. A. (2009). Fearful faces but not fearful eyes alone delay attention disengagement in 7-month-old infants. Emotion, 9(4), 560-565. https://doi.org/10.1037/a0015806

Pemberton Roben, C. K., Bass, A. J., Moore, G. A., Murray-Kolb, L., Tan, P. Z., Gilmore, R. O., ... Teti, L. O. (2012). Let me go: The influences of crawling experience and temperament on the development of anger expression. Infancy, 17(5), 558-577. https://doi.org/10.1111/j.1532-7078.2011.00092.x 
Pérez-Edgar, K., Morales, S., LoBue, V., Taber-Thomas, B. C., Allen, E. K., Brown, K. M., \& Buss, K. A. (2017). The impact of negative affect on attention patterns to threat across the first 2 years of life. Developmental Psychology, 53(12), 2219-2232. https://doi.org/10.1037/dev0000408

Pool, E., Brosch, T., Delplanque, S., \& Sander, D. (2015). Attentional bias for positive emotional stimuli : A meta-analytic investigation. Psychological Bulletin, 142(September), 79-106. https://doi.org/10.1037/bu10000026

Quinn, P. C., Yahr, J., Kuhn, A., Slater, A. M., \& Pascalis, O. (2002). Representation of the gender of human faces by infants: A preference for female. Perception, 31(9), 1109-1121. https://doi.org/10.1068/p3331

Safar, K., Kusec, A., \& Moulson, M. C. (2017). Face experience and the attentional bias for fearful expressions in 6- and 9-month-old infants. Frontiers in Psychology, 8(September). https://doi.org/10.3389/fpsyg.2017.01575

Safar, K., \& Moulson, M. C. (2017). Recognizing facial expressions of emotion in infancy: A replication and extension. Developmental Psychobiology, 59(4), 507514. https://doi.org/10.1002/dev.21515

Soussignan, R., Dollion, N., Schaal, B., Durand, K., Reissland, N., \& Baudouin, J. Y. (2017). Mimicking emotions: how 3-12-month-old infants use the facial expressions and eyes of a model. Cognition and Emotion, 32(4), 827-842. https://doi.org/10.1080/02699931.2017.1359015

Sugden, N. A., Mohamed-Ali, M. I., \& Moulson, M. C. (2014). I spy with my little eye: 
Typical, daily exposure to faces documented from a first-person infant perspective. Developmental Psychobiology, 56(2), 249-261. https://doi.org/10.1002/dev.21183

Tottenham, N., Tanaka, J. W., Leon, A. C., McCarry, T., Nurse, M., Hare, T. A., ... Nelson, C. (2009). The NimStim set of facial expressions: Judgments from untrained research participants. Psychiatry Research, 168(3), 242-249. https://doi.org/10.1016/j.psychres.2008.05.006

Ueno, M., Uchiyama, I., Campos, J. J., Dahl, A., \& Anderson, D. I. (2012). The organization of wariness of heights in experienced crawlers. Infancy, 17(4), 376392. https://doi.org/10.1111/j.1532-7078.2011.00083.x

Vaish, A., Grossmann, T., \& Woodward, A. (2008). Not all emotions are created equal: the negativity bias in social-emotional development. Psychological Bulletin, 134(3), 383-403. https://doi.org/10.1037/0033-2909.134.3.383

Vuilleumier, P. (2002). Facial expression and selective attention. Current Opinion in Psychiatry, 15(3), 291-300. https://doi.org/10.1097/00001504-200205000-00011

Whitney, P. G., \& Green, J. A. (2011). Changes in infants' affect related to the onset of independent locomotion. Infant Behavior and Development, 34, 459-466. https://doi.org/10.1016/j.infbeh.2011.05.001

Zachry, A. H., Chappell, L. H., Cox, V. H., Lopez, E. H., Mitchell, A. W., \& Woodard, L. (2015). Differences in the angry behaviors of precrawling and crawling infants. Journal of Education and Human Development, 4(2(1)), 67-72. https://doi.org/10.15640/jehd.v4n2 
Zumbahlen, M. R., \& Crawley, A. (1996). Infants' early referential behavior in prohibition contexts: The emergence of social referencing. Infant Behavior and Development, 19, 244. 


\section{CURRICULUM VITAE}

\section{Education History:}

Ph.D. University of Louisville: Louisville, KY, 2019

Dissertation: "Disentangling the Negativity Bias: 7-9-Month-Old Crawling and Non-Crawling Infants' Responses to Fearful and Angry Expressions" Major: Experimental Psychology: Cognition and Development Advisor: Cara Cashon, Ph.D.

M.S. University of Louisville: Louisville, KY, 2017 Major: Experimental Psychology: Cognition and Development Advisor: Cara Cashon, Ph.D.

M.A. University of Tennessee: Knoxville, TN, 2014

Thesis: "Neural Correlates of Face Processing: Perceptual Narrowing and Categorization" Major: Experimental Psychology

Advisor: Greg Reynolds, Ph.D.

B.A. University of Tennessee: Knoxville, TN, 2007

Major: Psychology

\section{$\underline{\text { Publications }}$}

The ManyBabies Consortium. (in press). Quantifying sources of variability in infancy research using the infant-directed speech preference. Advances in Methods and Practices in Psychological Science (AMPPS).

Cashon, C. H. \& Dixon, K. C. (2020). Face perception. In M. Harris \& G. Westermann (Eds.), The encyclopedia of child and adolescent development: Vol. 3 Cognition. John Wiley \& Sons, Inc.

Dixon, K. C., Reynolds, G. D., Romano, A. C., Roth, K. C., Stumpe, A. L., Guy, M. W., \& Mosteller, S. M. (2019). Neural correlates of individuation and categorization of other-species faces in infancy. Neuropsychologia, 126, 27-35. https://doi.org/10.1016/J.NEUROPSYCHOLOGIA.2017.09.037 
Guy, M. W., Reynolds, G. D., Mosteller, S. M., \& Dixon, K. C. (2017). The effects of stimulus symmetry on hierarchical processing in infancy. Developmental Psychobiology, 59(3), 279-290.

Conference Presentations (peer-reviewed):

Olesen, N.M., Dixon, K.C., Mervis, C.B., \& Cashon, C.H. (October, 2019). Emotional facial expression preference in toddlers with Williams syndrome. Poster presented at the Poster presented at the biennial meeting of the Cognitive Development Society, Louisville, Kentucky.

Dixon, K.C., Holt, N.A., Olesen, N.M., Mervis, C.B., \& Cashon, C.H. (July, 2018). Causal Perception of Michottian Launching Events by Toddlers with Williams Syndrome? Poster presented at the biennial meeting of the International Congress on Infant Studies, Philadelphia, Pennsylvania.

Olesen, N.M., Dixon, K.C., Crenshaw, R.D., Holt, N.A., \& Cashon, C.H. (July, 2018). The Effects of Parental Interaction on Infant Learning: When Less is More. Poster presented at the biennial meeting of the International Congress on Infant Studies, Philadelphia, Pennsylvania.

Olesen, N.M., Dixon, K.C., Holt, N.A., Dale, L.E., Cashon, C.H. (October, 2017). Do Babies See Faces in Face, Face-like, and Ambiguous Stimuli? Pareidolia in Infancy. Poster presented at the Poster presented at the biennial meeting of the Cognitive Development Society, Portland, Oregon.

Holt, N.A., Pal, P., Olesen, N.M., Dixon, K.D., Cashon, C.H. (April, 2017). Parent interaction disrupts 4-month-old infants' learning about causality during sticky mittens training. Paper presented at the biennial meeting of the Society for Research in Child Development, Austin, Texas.

Dixon, K.C., Olesen, N.M., Kondaurova, M., Woodruff-Borden, J., \& Cashon, C.H. (April, 2017). Prosody of IDS and maternal negative affect: An investigation of mothers from a community sample. Poster presented at the biennial meeting of the Society for Research in Child Development, Austin, Texas.

Dixon, K.C., Holt, N.A., Woodruff-Borden, J., \& Cashon, C.A. (October, 2015). Same visual input, different cognitive outcome: Differences in 5-month-olds' emotion discrimination, but not visual scanning behavior. Poster presented at the biennial meeting of the Cognitive Development Society, Columbus, Ohio. 
Dixon, K. C., Mosteller, S., Guy, M. W., Capps, S. C., Frix, K. L., \& Reynolds, G. D. (March, 2015). Neural correlates of other-species face processing in infancy: Perceptual narrowing and categorization. Poster presented at the biennial meeting of the Society for Research in Child Development, Philadelphia, Pennsylvania.

Guy, M. W., Dixon, K. C., Mosteller, S., Leeper, A. D., Ciesielski, C. L., \& Reynolds, G. D. (March, 2015). Effects of stimulus symmetry and individual differences on hierarchical visual processing in six-month-old infants. Poster presented at the biennial meeting of the Society for Research in Child Development, Philadelphia, Pennsylvania.

Mosteller, S., Guy, M. W., Dixon, K. C., Capps, S. C., Frix, K. L., Connell, J. P., \& Reynolds, G. D. (March, 2015). The effect of local element density on processing of visual hierarchical patterns: An infant ERP study. Poster presented at the biennial meeting of the Society for Research in Child Development, Philadelphia, Pennsylvania.

Dixon, K. C., Mosteller, S. M., Guy, M. W., McGirl, L. E., Scruggs, A. M., Singh, M. F., \& Reynolds, G. D. (November, 2013). Covert orienting and visual attention in 4month-old infants. Poster presented at the annual meeting of the International Society for Developmental Psychobiology.

Guy, M. W., Dixon, K. C., Mosteller, S. M., Davis, J. H., Pilkay, S. R., McGirl, L. E., Scruggs, A. M., Singh, M. F., \& Reynolds, G. D. (November, 2013). The impact of symmetry on hierarchical processing in 6-month-old infants. Poster presented at the annual meeting of the International Society for Developmental Psychobiology.

Mosteller, S. M., Guy, M. W., Dixon, K. C., Scruggs, A. M., McGirl, L. E., Singh, M. F., \& Reynolds, G. D. (November, 2013). Infant visual attention and neural correlates of saccade planning in a spatial cueing task. Poster presented at the annual meeting of the International Society for Developmental Psychobiology.

Other Presentations:

Dixon, K.C. \& Rodems, M. (April 2017). Applied careers for research psychologists. Talk presented at the experimental brown bag, University of Louisville, Kentucky. 
Dale, L.E., Dixon, K.C., Olesen, N.M., Holt, N.A., \& Cashon, C.H. (April, 2017). Infants' Perception of Faces in Face-Like and Ambiguous Images. Poster presented at the University of Louisville Undergraduate Research and Community Engagement Symposium.

Dixon, K.C. (March, 2017). Neural correlates of categorization of other-species faces in infancy. Talk presented at the experimental brown bag, University of Louisville, Kentucky.

Thompson, Q.M., Dixon, K.C., Olesen, N.M., Kondaurova, M., Woodruff-Borden, J., \& Cashon, C.H. (April, 2016). Maternal negative affect and infant directed speech. Poster presented at the University of Louisville Undergraduate Research and Community Engagement Symposium.

Dixon, K.C. (November, 2015). Negative affect and speech characteristics. Talk presented at the experimental brown bag, University of Louisville, Kentucky.

Dixon, K.C., Holt, N.A., Woodruff-Borden, J., \& Cashon, C.A. (October, 2015). Same visual input, different cognitive outcome: Differences in 5-month-olds' emotion discrimination, but not visual scanning behavior. Poster presented at the annual meeting of Research! Louisville, Louisville, Kentucky.

Research Experience:

Infant Cognition Laboratory 2014 - current University of Louisville, Louisville, KY Department of Psychological and Brain Sciences Supervisor: Cara Cashon, Ph.D.

Lab Manager (2019 - current)

Graduate Research Assistant (2015 - 2016, 2017 - 2018)

Graduate Fellow (2014 - 2015, 2018 - 2019)

Developmental Cognitive Neuroscience Laboratory

$2012-2014$

University of Tennessee, Knoxville, TN

Department of Psychology

Supervisor: Greg Reynolds, Ph.D.

Graduate Research Assistant

Center for Parenting University of Tennessee, Knoxville, TN

$2011-2012$

Department of Child and Family Studies

Supervisor: Heidi Stolz, Ph.D.

Graduate Research Assistant 


\section{Teaching Experience:}

Graduate Teaching Assistant \& Lab Instructor (50 students, two sections)

University of Louisville, Louisville, KY

Department of Psychological and Brain Sciences

Research Methods for Psychology

Instructor: Marci DeCaro, Ph.D.

July 2016 - June 2017

Graduate Teaching Assistant (100+ students)

University of Tennessee, Knoxville, TN

Department of Psychology

Child Psychology

Instructor: Greg Reynolds, Ph.D.

January 2013 - May 2013

August 2013 - May 2014

Grants Awarded:

University of Louisville College of Arts \& Sciences Graduate Student Grant for Research and Creative Activities. Infant Preferences for and Reactions to Emotional Facial Expressions. 2018-2019. Amount \$500.00

University of Louisville College of Arts \& Sciences Graduate Student Grant for Research and Creative Activities. Coding Micro-expressions in Infants. 20162017. Amount $\$ 711.00$

Honors:

2019 - Society for Improvement of Psychological Science Mission Award for improving psychological science in the face of challenge, as contributor to the ManyBabies1 Collaboration

$2014-2015$,

2018 - 2019 - Graduate Fellowship

2018 - GNAS Research Funds Award (\$100)

2017 - Experimental Psychology Faculty Award for Excellence in Research (Junior)

2017 - Graduate Dean's Citation 
2017 - Society for Research in Child Development Conference Travel Award (\$300) 2017 - GSC Travel Award $(\$ 350)$

2017 - GNAS Research Funds Award (\$100)

2016 - GSC Travel Award (\$350)

2014 - Society for Research in Child Development Conference Travel Award (\$300)

2014 - GSU (\$100) \& GSC (\$350) Travel Awards

2014 - Graduate Fellowship at University of Louisville (2 years)

2013 - Graduate Student Senate Travel Award (\$100)

2013 - International Society for Developmental Psychobiology Travel Award

2013 - Department Travel Award

2007 - Graduated Summa Cum Laude with a B.A. in Psychology

2005 - 2007 - Golden Key Honor Society

2005 - 2007 - Honor Society of Phi Kappa Phi

2004 - 2007 - Gamma Beta Phi Honors Society

Professional development:

Grant Writing Academy, University of Louisville, Spring 2017

Professional society memberships:

Kentucky Academy of Science (KAS, 2018-present)

Association for Psychological Science (APS, 2017-present)

American Association for the Advancement of Science (AAAS, 2015-present)

Society for Research in Child Development (SRCD, 2015-present)

Cognitive Development Society (CDS, 2015-present)

International Congress on Infant Studies (ICIS, 2014- present) 
Kentucky Psychological Association (KPA, 2014-2015)

APA Student Affiliate (2012-2014)

International Society for Developmental Psychobiology (ISDP, 2012-2013)

Outreach/professional service:

Experimental Student Representative, May 2016 - May 2018

Student Reviewer for the Society for Research in Child Development (SRCD) Biennial Meeting, September 2016

Dupont Manual Regional Science Fair Judge, 2015

Brain Awareness Week presentation, Belle Morris Elementary School, Knoxville, TN March 2014

Brain Awareness Week presentation, Farragut Elementary School, Knoxville, TN March 2012 